\title{
A Simulation Model To Optimize The Painting Robots
}

\author{
K. Nuntiya ${ }^{1}$, C. Seksan ${ }^{1}$, T. Dechathanat ${ }^{1 *}$, W. Fasai ${ }^{1}$, S. Pramot ${ }^{2}$ and A.H. Ismail ${ }^{3 *}$ \\ ${ }^{1}$ Faculty of Engineering, Pathumwan Institute of Technology, Bangkok Thailand \\ ${ }^{2}$ Faculty of Engineering, Kasem Bundit University, Bangkok 10250, Thailand \\ ${ }^{3}$ School of Mechatronic Engineering, Universiti Malaysia Perlis, Malaysia
}

Received: November 18, 2019; Accepted: November 22, 2019; Published: February 7, 2020

*Corresponding author: AT. Dechathanat, 1Faculty of Engineering, Pathumwan Institute of Technology, Bangkok Thailand, E-mail: thewan. thong@gmail.com

\begin{abstract}
Robots have been widely used to replace human labors in the manufacturing factories, especially when dealing with hazardous environments such as chemicals, heat, etc. Other objective including ensuring consistent quality taking advantages of continuous operation of the robots. However, one major hindrance is the high initial investment of the robots despite the benefit acquired when the robots is used. Often, the skeptical opinion of the investors winding down the proposal. Therefore, the simulation of process improvement activities especially on the robot-based production process is a subject of great interest, which requires low to no-cost without jeopardizing the investor trust. In the ceramic factory, different value products are produced. Finding the highest benefit from robotics is something to consider. In this study, a simulation software, namely FlexSim is analyzed and simulated to optimize the painting process by robots.
\end{abstract}

Keywords: Simulation; Productivity; Motion and time study; Optimization; Painting robots.

\section{Introduction}

There are many industrial processes in the ceramic factories, for instance the forming process, handling process, and packing process as well as the use of robots for spraying process. These robots are known as painting robot. Ceramic factories are also exposed to uncomfortable environment i.e. lot of dust, heat and bad smell causing resignation rate problems higher that other industries such as semiconductors, car manufacturers and so on Thus, the use of robots is significant enough in this industry. In addition, robot operation can achieve consistent product quality, continuous operation, and easy operation depending on product characteristics. On the other hand, the use of robots possesses its own disadvantages, for instance the high investment cost at the initial project, the need of highly skilled staff to underwritten and modify the programs and also high maintenance cost. Therefore, the management and engineer must have a proper planning on the robot application involving the specific product and process which required a thorough analysis to maximize benefit from robot applications in the industry.

For production process analysis activities, there are many engineering conventional tools and simulation software are widely used [1]. For instances, value stream mapping [2,3], Lean [4], six-sigma [5], TQM [6], Toyota production system [7], Arena simulation software [8,9], Delmia [10,11]. The development of optimization models for maximizing profits $[12,13]$ applied to evaluate the solutions. Engineering economic tool [11] is another indicator commonly used in project selection specially for projects that require a large investment or a lot of resources. In this research, due to the factory has different value products in both production cost, output that can be produced in each day and different selling prices, a simulation model from FlexSim software [14] is developed for optimizing in the painting robots of tableware ceramic production in Thailand. The comparison between current process and proposed process by simulation are throughput, productivity (unit per hour, UPH), as well as the number of workers. The determination of the production conditions for the ceramics painting process in order to get the optimization of painting robots will also be the important goal of this study.

\section{Current Situation}

\section{Painting Process Layout}

Currently, the painting process consist of 3 stationary robots which perform painting in different positions. The flow chart for painting process is shown in Fig. 1

Station- 1 is assigned for painting on the outside surface of the products. There are two robots in this station. Robot 1 will paint on product's surface position 1 , robot 2 will paint on product's surface position 2 . Station-2 will paint on the inside of the product. Finally, the 3rd station paint the pattern of the product. Station- 2 and station-3 also have two robots similar to station-1. Robot 1 paint on product's surface position 1 and robot 2 paint on product's surface position 2 . In this study, the product under investigation is the bakeware such as the plate. Fig. 2 shows the two painting production processes by using six stationary robots. 


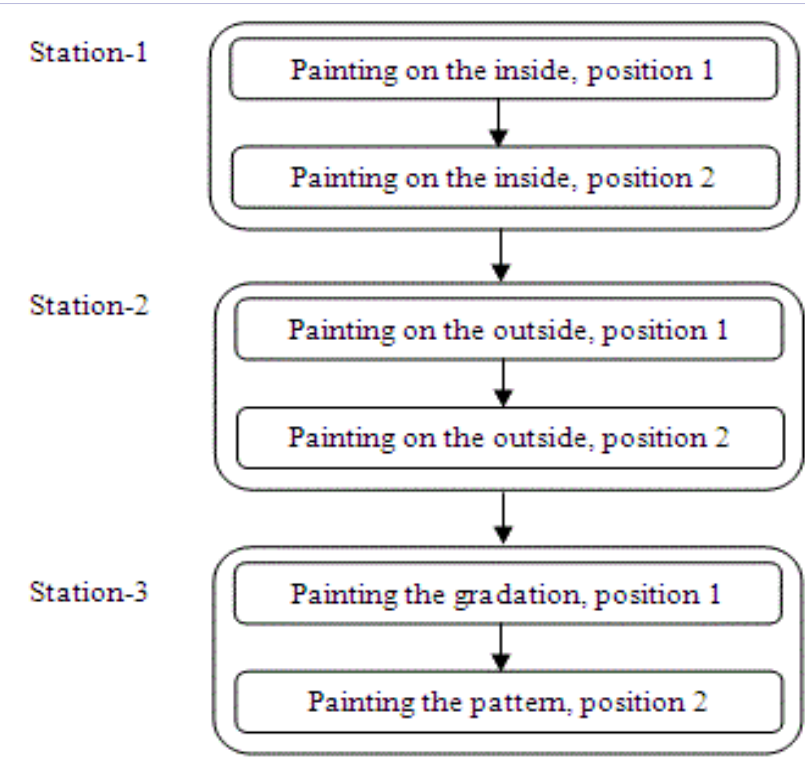

Figure 1: Flow chart for ceramic painting process

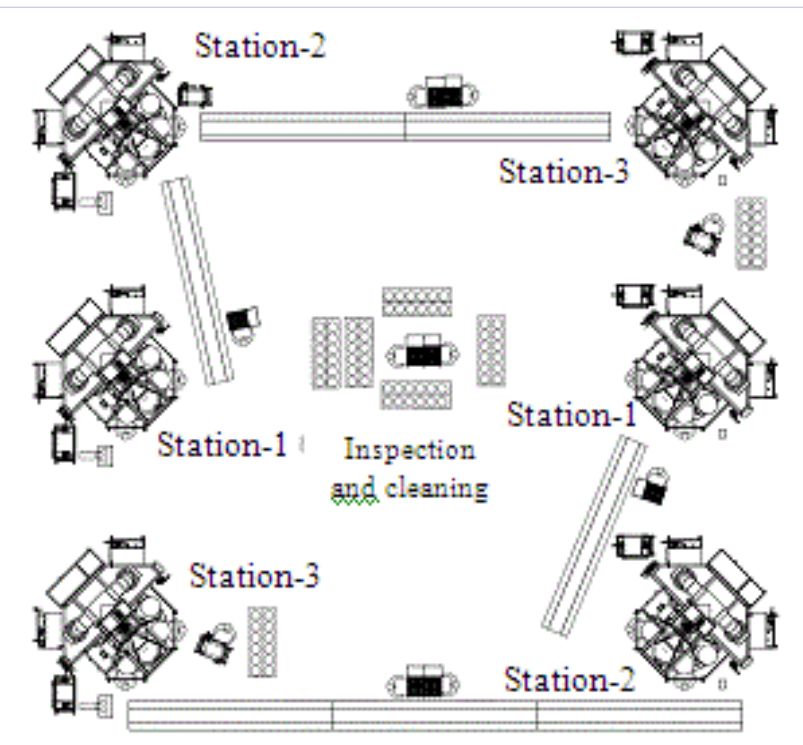

Figure 2: Current layout of painting process using robots

\section{Motion and time study}

The study of time and movement of the current painting process conditions of the plate is depicted in Fig. 3. It is found that there are three ceramic painting stations, in which each station has two painting robots. So, for the painting process is required six painting robots to finish the job. The total cycle time of the whole painting process is 481 seconds per one piece. The painting process took a long time, required a lot of labors although the painting process uses six robots. Prior to primary issues of feasibility of the use of robots, with the high investment cost, the issues raised by the investors is now being questioned.
Is it worth to use the robots?

The answer these questions, the production processes need to be re-design. Re-designing the production processes tin order to increase the works efficiency by using the concept of eliminating, combining, rearranging and simplifying will help to increase productivity, reduce the costs, and ultimately be able to use painting robots to its maximum capacity.

\begin{tabular}{|c|c|c|c|c|c|c|c|}
\hline \multicolumn{4}{|l|}{ sas:an: Pointingrobat } & \multicolumn{4}{|c|}{ Summery } \\
\hline \multicolumn{4}{|l|}{ Betwat: Bokengre } & \multicolumn{2}{|c|}{ Type } & \multicolumn{2}{|c|}{ Present Proposed } \\
\hline \multicolumn{4}{|l|}{ Dote: 25-3ul-19 } & \multicolumn{2}{|c|}{ Operation } & 25 & \\
\hline \multicolumn{4}{|c|}{ Ansylyt : P rocess engineer } & \multicolumn{2}{|c|}{ Trensport } & 3 & \\
\hline \multirow{2}{*}{\multicolumn{4}{|c|}{ 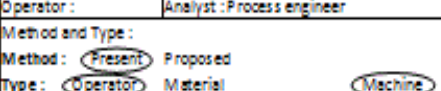 }} & \multicolumn{2}{|c|}{ Dear } & 0 & \\
\hline & & & & \multirow{2}{*}{\multicolumn{2}{|c|}{\begin{tabular}{|l} 
Inspestion \\
Stres:
\end{tabular}}} & 1 & \\
\hline type: Cperator Msterial & \multicolumn{3}{|c|}{ (vachine } & & & 0 & \\
\hline \multirow{2}{*}{\multicolumn{4}{|c|}{$\begin{array}{l}\text { Yeild : } \\
\text { Mat Margin }[86 \text { : }\end{array}$}} & \multicolumn{2}{|c|}{ Time (ax) } & 481 & \\
\hline & & & & \multirow{2}{*}{\multicolumn{2}{|c|}{\begin{tabular}{|l|}
$\operatorname{Sin}=(m)$ \\
$\operatorname{Cost}$
\end{tabular}}} & 25 & \\
\hline & & & & & & & \\
\hline Event Description & \multicolumn{5}{|c|}{ symbol } & (Sime- & 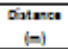 \\
\hline Irspestion & & \multicolumn{3}{|c|}{ 5101 } & $\nabla$ & 18 & \\
\hline Glening bisout with water. & & c) & $D$ & $\square$ & $\nabla$ & 23 & \\
\hline Elening by waterand ape on the bgo & & 드 & D & $\square$ & $\nabla$ & 29 & \\
\hline Losding prosuct to station 1 & & 도 & D & $\square$ & $\nabla$ & 13 & 25 \\
\hline More to Robot:a1-1 & & 도 & D & $\square$ & $\nabla$ & 2 & \\
\hline Eprs/ col lork1 position 1 & & C) & D & $\square$ & $\nabla$ & 20 & \\
\hline More to Ro bot:1-2 & & ch & $D$ & $\square$ & $\nabla$ & 5 & \\
\hline Spres/color:1 position 2 & & $\Rightarrow$ & D & $\square$ & $\nabla$ & 15 & \\
\hline MVee to un losding station & & C) & $D$ & $\square$ & $\nabla$ & 2 & \\
\hline Uniosding the produst to conveyor & & C) & $D$ & $\square$ & $\nabla$ & 9 & 29 \\
\hline More to station 2 & 0 & D & $D$ & $\square$ & $\nabla$ & 18 & 12 \\
\hline Cosding product to stotion 2 & & D & D & $\square$ & $\nabla$ & 10 & \\
\hline More to Robotat2-1 & & 口 & $D$ & $\square$ & $\nabla$ & 5 & \\
\hline Epre/ co ior:2 position 1 & & C) & $D$ & $\square$ & $\nabla$ & 23 & \\
\hline More to Robotaz2-2 & & C & $D$ & $\square$ & $\nabla$ & 5 & \\
\hline Epres/colort2 position 2 & & C & $\mathrm{D}$ & 两 & $\nabla$ & 21 & \\
\hline More to un losding station & & $\Rightarrow$ & $D$ & $\square$ & $\nabla$ & 2 & \\
\hline Unlosding the produst to comeryor & & C) & $D$ & $\square$ & $\nabla$ & 9 & 29 \\
\hline More to station 3 & 0 & 다 & D & $\square$ & $\nabla$ & 18 & 3 \\
\hline More to Finish by corvefor & 0 & E) & $D$ & $\square$ & $\nabla$ & 18 & 3 \\
\hline Finishing & & 당 & $\mathrm{D}$ & $\square$ & $\nabla$ & 94 & \\
\hline Losd ing prosuct to strtion 3 & & c) & $D$ & $\square$ & $\nabla$ & 10 & \\
\hline More to fobott3-1 & & C) & D & $\square$ & $\nabla$ & 5 & \\
\hline Epra/ color:3 position 1 & & C) & $D$ & $\square$ & $\nabla$ & 23 & \\
\hline More to Ro bot:a-2 & & C & D & $\square$ & $\nabla$ & 5 & \\
\hline Eprg/ co lork3 position 2 & & C & $D$ & $\square$ & $\nabla$ & 21 & \\
\hline More to un losding station & & C & $D$ & $\square$ & $\nabla$ & 5 & \\
\hline Unlosding productend Polighing & & C) & D & $\square$ & $\nabla$ & 21 & \\
\hline Fiening transfer prod ut to car rack. & & 口 & $D$ & $\square$ & $\nabla$ & 28 & \\
\hline
\end{tabular}

Figure 3: Flow chart for ceramic painting process

\section{Productivity}

We observed the productivity at each hour at painting production line no.1, during June - August 2019 as shown in Fig. 4. The output was measured in term of unit per hour, UPH. The average UPH of each month are similar which is around 110.

To optimize the painting robots, to choose the right product types for this painting production process by considering the benefits that will be the main key as an indicator. Designing a new painting production process to reduce the losses that occur in the old painting production process. Then make a simulation to analyze the output that will be get from the process. Because the factory needs to find the solution that what kind of product the factory should produce and how much. The profit maximize equation was created for calculating the right answer. Process limitations 
will be used as the constraints to determine the amount of output obtained from the equation. Selling price and production cost in terms of production time will be an important variable in the equation. Finally, summarize the guidelines for process improvement and propose the most profitable production planning methods.

\section{Methodology}

\section{Production process and layout design}

From the analysis of the characteristics of the ceramic plate painting, it is found that although the top and bottom colors are the same color, but due to the limitations of robots that cannot be painted in the bottom position. Resulting in using 2 painting stations to spray the top 1 station and the bottom by another station. Therefore, a new method of painting has been proposed by using an automated spray booth that is specially designed to suit the shape and size of the ceramic plate. The design results will be able to paint the top and bottom of the ceramic plate at the same time and same station. As shown in Fig. 5 new painting production process layout, the proposed production layout is based on the objective in order to use the robot as efficient as possible. Since this factory currently has 6 robot stations, the production plan that can use the robot to the maximum benefit should have 6 production lines or 6 painting lines for ceramic plate type.

However, this production process design cannot be used with other products with 2 colors. Because the color of the top and bottom are different. As a result, cannot be painted in the same station. The suitable painting production process for 2-colors product group has been designed as in Fig. 6 which is the layout of 3-painting processes for 2-colors wares using robots. Station-1 designed for painting on the outside surface of the products. Station-2 will bereplaced by automated spray booth with fix four spray guns for painting on the inside of the product. The 3rd station painting the pattern of the product. For station-2, the staff will be responsible for feeding the workpiece into the automated spray booth. Then press the button to operate the painting system automatically. Then took the piece out when the specified working time has elapsed. Although this station is not painted with painting robots but can also work automatically. The other different from using robots is the setting is done by hand, which has a scale while the painting robots will use the program setting.

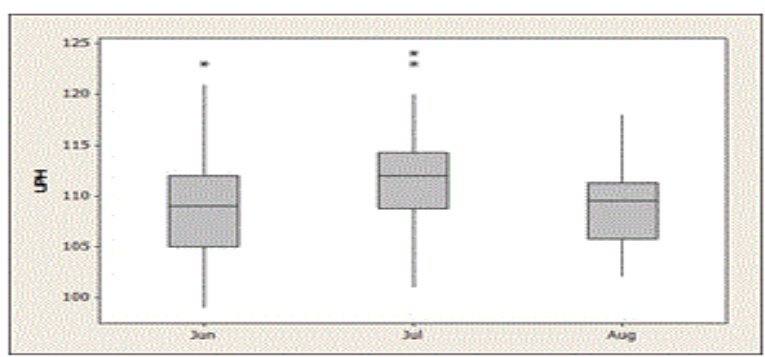

Figure 4: Current productivity UPH of painting robots

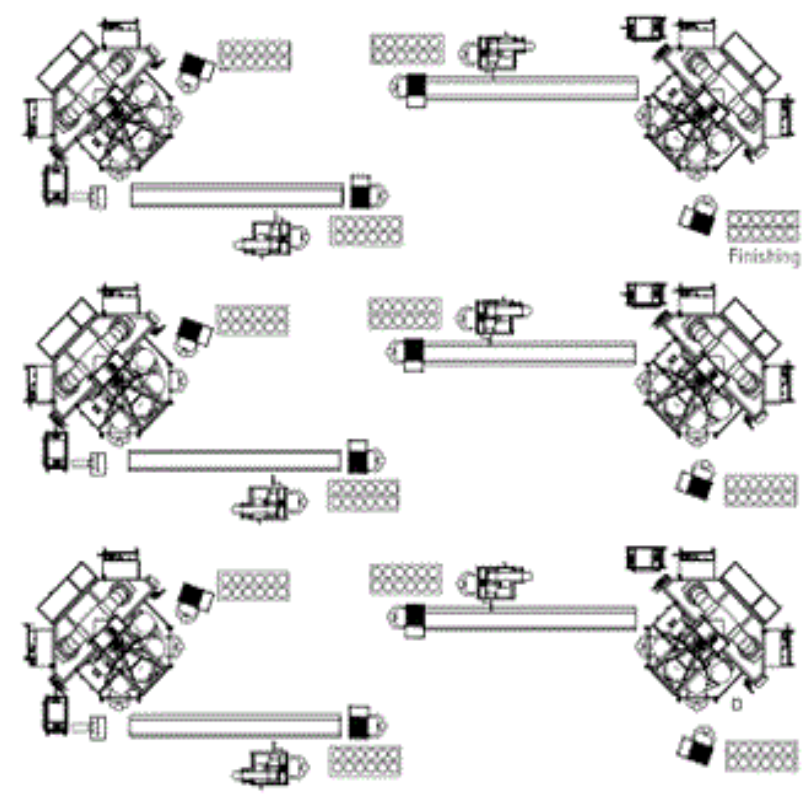

Figure 5: Proposed layout of 6-painting processes for single color wares

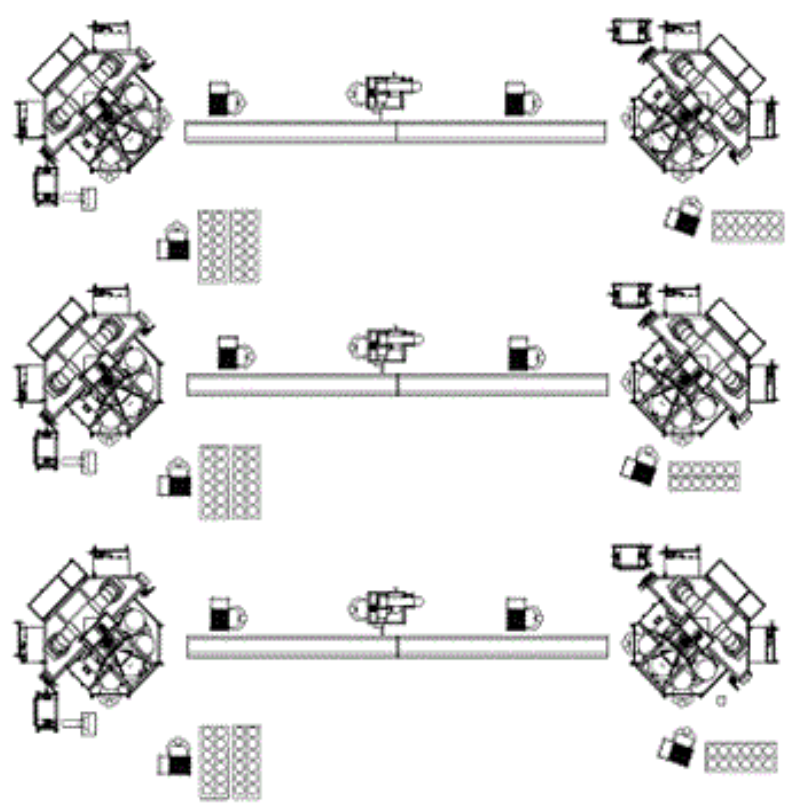

Figure 6: Current layout of painting process using robots

\section{Motion and time study}

After designed the painting production process layouts and process flow charts, the next step will be to study the time and motion of both processes of single-color painting wares and 2-colors painting wares. 
Process engineers and ceramic technical engineers who has experienced in ceramic manufacturing process and quality control determined the appropriate painting production process that can make production possible for ceramic wares. Take the operation time by reference from similar products and production processes. The motion and time study in Fig. 7 presented that with 5 workers, the total cycle time of the proposed painting process for single color ware is 103 seconds per one piece. The distance of movement of the painting production process is reduced to 9 meters.

While the motion and time study for 2-colors ceramic wares in Fig. 8 presented that with 10 workers, the total cycle time of the proposed painting process is reduced from 481 seconds to 370 seconds. The distance of movement of the painting production process is reduced from 26 meters to 17 meters.

The layout of the proposed painting production processes resulting in reducing the number of workers, cycle time and the distance of painting production, lead to the process simulation by FlexSim software.

\begin{tabular}{|c|c|c|c|c|c|c|c|}
\hline \multirow{2}{*}{\multicolumn{4}{|c|}{\begin{tabular}{|l|} 
Deation: Painting robot \\
Acturity: Bakeware \\
\end{tabular}}} & \multicolumn{4}{|c|}{ Summary } \\
\hline & & & & \multicolumn{2}{|l|}{ Type } & \begin{tabular}{|l|l} 
Present \\
\end{tabular} & Proposed \\
\hline \multicolumn{4}{|l|}{ Date : $\quad 25$-Aug-19 } & \multicolumn{2}{|c|}{ Operation } & 25 & 11 \\
\hline \multirow{2}{*}{\multicolumn{4}{|c|}{$\begin{array}{l}\text { Operat or: } \\
\text { Method and Type: }\end{array}$}} & \multicolumn{2}{|c|}{ Transport } & 3 & 3 \\
\hline & & & & \multirow{2}{*}{\multicolumn{2}{|c|}{\begin{tabular}{|l} 
Delay \\
inspection \\
\end{tabular}}} & 0 & 0 \\
\hline \multirow{2}{*}{$\begin{array}{l}\text { Method: Present Proposed } \\
\text { Type: Operaton Materlal }\end{array}$} & \multirow{2}{*}{\multicolumn{3}{|c|}{ (Machine) }} & & & 1 & 1 \\
\hline & & & & \multicolumn{2}{|c|}{ 5torage } & 0 & - \\
\hline \multirow{2}{*}{\multicolumn{4}{|c|}{$\begin{array}{l}\text { Yelld: } \\
\text { Mat.Margin (\%) : }\end{array}$}} & \multicolumn{2}{|c|}{ Time (sec) } & 481 & 370 \\
\hline & & & & Dustar & $\cos (\mathrm{m})$ & 26 & 17 \\
\hline & & & & \multicolumn{2}{|c|}{ Cost } & & \\
\hline Event Description & \multicolumn{5}{|c|}{ Symbol } & $\begin{array}{c}\text { Time } \\
{[\text { [Second }]}\end{array}$ & $\begin{array}{c}\text { Destance } \\
{[\mathrm{m}]}\end{array}$ \\
\hline Inspection & 0 & 5 & $\theta$ & & $\nabla$ & 18 & \\
\hline Cleaning biscult with water. & & ㄷ) & D & $\square$ & $\nabla$ & 23 & \\
\hline Cleaning by water and tape on the logo & & $\Rightarrow$ & D & $\square$ & $\nabla$ & 29 & \\
\hline Loading product to station 1 & & $\Rightarrow$ & D & $\square$ & $\nabla$ & 13 & 2.5 \\
\hline \begin{tabular}{|l|} 
Move to Robot $\neq 1-1$ \\
\end{tabular} & & $\Rightarrow$ & D & $\square$ & $\nabla$ & 5 & \\
\hline Spray colort\#1 position 1 & & $\Rightarrow$ & D & $\square$ & $\nabla$ & 20 & \\
\hline Move to Robot:m1-2 & & 5 & D & $\square$ & $\nabla$ & 5 & \\
\hline Spray color"\#1 position 2 & & $c$ & D & $\square$ & $\nabla$ & 15 & \\
\hline Move to unioading station & & $\Rightarrow$ & D & $\square$ & $\nabla$ & 5 & \\
\hline \begin{tabular}{|l} 
Unioading the product to corveyor \\
\end{tabular} & & 5 & D & $\square$ & $\nabla$ & 9 & 2.5 \\
\hline Move to station2 & 0 & D & D & $\square$ & $\nabla$ & 37 & 6 \\
\hline Auto spray booths & c & $\Rightarrow$ & D & $\square$ & $\nabla$ & 74 & \\
\hline Move to Finish by conveyor & 0 & $\Rightarrow$ & D & $\square$ & $\nabla$ & 18 & 3 \\
\hline Finishing & e & 5 & D & $\square$ & $\nabla$ & 94 & \\
\hline Move to Finish by conveyor & 0 & D. & D & $\square$ & $\nabla$ & 18 & 3 \\
\hline Loading product to station 3 & 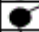 & $\Rightarrow$ & D & $\square$ & $\nabla$ & 10 & \\
\hline \begin{tabular}{|l|} 
Move to Robot A3-1 \\
\end{tabular} & & 5 & D & $\square$ & $\nabla$ & 5 & \\
\hline Spray color\#3 position 1 & & c) & D & $\square$ & $\nabla$ & 23 & \\
\hline Move to Riobot:A3-2 & & $\Rightarrow$ & D & $\square$ & $\nabla$ & 5 & \\
\hline Spray color\#3 position 2 & & c) & D & $\square$ & $\nabla$ & 21 & \\
\hline Move to unioading station & & c) & D & $\square$ & $\nabla$ & 5 & \\
\hline Unloading product and Pollshing & & $\Rightarrow$ & D & $\square$ & $\nabla$ & 21 & \\
\hline Cleaning transfer product to carrack & & $\Rightarrow$ & D & $\square$ & $\nabla$ & 28 & \\
\hline
\end{tabular}

Figure 7: Motion and time study of proposed layout for single color wares

\begin{tabular}{|c|c|c|c|c|c|c|}
\hline \multirow{2}{*}{\multicolumn{3}{|c|}{\begin{tabular}{|l|} 
Location: Painting robot \\
Activity: Bakeware
\end{tabular}}} & \multicolumn{4}{|c|}{ Summary } \\
\hline & & & \multicolumn{2}{|l|}{ Type } & \begin{tabular}{|l|} 
Present \\
\end{tabular} & Proposed \\
\hline \multicolumn{3}{|l|}{ Date: $\quad 25$-Aug-19 } & \multicolumn{2}{|c|}{ Operation } & 25 & 11 \\
\hline \multicolumn{3}{|l|}{ Analyst : Process engineer } & \multicolumn{2}{|c|}{ Transport } & 3 & 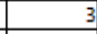 \\
\hline Method and Type : & & & \multicolumn{2}{|c|}{ Delay } & 0 & \\
\hline \multicolumn{3}{|l|}{ Method: Present Proposed } & \multicolumn{2}{|c|}{ Inspection } & 1 & 1 \\
\hline Type: Operator Material & \multicolumn{2}{|c|}{ Machine } & \multicolumn{2}{|c|}{ Storage } & 0 & - \\
\hline \multirow{3}{*}{\multicolumn{3}{|c|}{$\begin{array}{l}\text { Yeild: } \\
\text { Mat.Margin (\%): }\end{array}$}} & \multicolumn{2}{|c|}{ Time (sec) } & 481 & 370 \\
\hline & & & \multirow{2}{*}{\multicolumn{2}{|c|}{\begin{tabular}{|l|}
$\mid$ Dist ance $(\mathrm{m}]$ \\
Cost
\end{tabular}}} & 26 & 17 \\
\hline & & & & & & \\
\hline Event Description & \multicolumn{4}{|c|}{ Symbol } & $\begin{array}{c}\text { Time } \\
\text { (Second) }\end{array}$ & $\begin{array}{c}\text { Distance } \\
\text { (m) }\end{array}$ \\
\hline Inspection & 5) & $\theta$ & $\square$ & $\nabla$ & 18 & \\
\hline Cleaning biscuit with water. & द & D & $\square$ & $\nabla$ & 23 & \\
\hline Cleaning by water and ta pe on the logo & 5 & D & $\square$ & $\nabla$ & 29 & \\
\hline Loading product to station 1 & $\Rightarrow$ & D & $\square$ & $\nabla$ & 13 & 2.5 \\
\hline Move to Robotit1-1 & द & D & $\square$ & $\nabla$ & 5 & \\
\hline Spray color\#1 position 1 & 5 & D & $\square$ & $\nabla$ & 20 & \\
\hline Move to Roboth1-2 & $\Rightarrow$ & D & $\square$ & $\nabla$ & 5 & \\
\hline Spray colorit1 position 2 & द & D & $\square$ & $\nabla$ & 15 & \\
\hline Move to unl oading station & 5 & D & $\square$ & $\nabla$ & 5 & \\
\hline Unloading the product to conveyor & $\Leftrightarrow$ & D & $\square$ & $\nabla$ & 9 & 2.5 \\
\hline Move to station2 & 21 & D & $\square$ & $\nabla$ & 37 & 6 \\
\hline Auto spray booths & 5 & D & $\square$ & $\nabla$ & 74 & \\
\hline Move to Finish by conveyor & ב & D & $\square$ & $\nabla$ & 18 & 3 \\
\hline Finishing & C) & D & $\square$ & $\nabla$ & 94 & \\
\hline Move to Finish by conveyor & C) & D & $\square$ & $\nabla$ & 18 & 3 \\
\hline Loading product to station 3 & 5 & $D$ & $\square$ & $\nabla$ & 10 & \\
\hline Move to Robot\#3-1 & $\Rightarrow$ & D & $\square$ & $\nabla$ & 5 & \\
\hline Spray color\#3 position 1 & 5 & D & $\square$ & $\nabla$ & 23 & \\
\hline Move to Roboti\#3-2 & 5 & D & $\square$ & $\nabla$ & 5 & \\
\hline Spray color\#3 position 2 & ᄃ) & D & $\square$ & $\nabla$ & 21 & \\
\hline Move to uniloading station & 5 & D & $\square$ & $\nabla$ & 5 & \\
\hline Unloading product and Polishing & 5 & D & $\square$ & $\nabla$ & 21 & \\
\hline Cleaning transfer product to car rack & $\Rightarrow$ & $D$ & $\square$ & $\nabla$ & 28 & \\
\hline
\end{tabular}

Figure 8: Motion and time study of proposed layout for 2-colors wares

\section{Simulation}

A FlexSim 3D simulation software was use in this studied. The advantages of FlexSim are models, simulates, predicts, and visualizes business systems in a variety of industries such as manufacturing, material handling, healthcare, warehousing, mining, logistics and more. It is both powerful and user-friendly.

Three painting production processes were simulation in this study. Which are consist of current painting process shown by Fig. 9, proposed painting process for single color wares shown by Fig. 10 and proposed painting process for 2-colors wares shown by Fig. 11 .

The parameters of each variables such as process flow, working time, number of workers and work procedures based on the motion and time study descripted in the previous paragraph. The distance of each stations will be positioned according to the current layout of the factory. Relocation the robot stations are very difficult because it requires people with specific skills. And there are expenses related to other systems as well. 


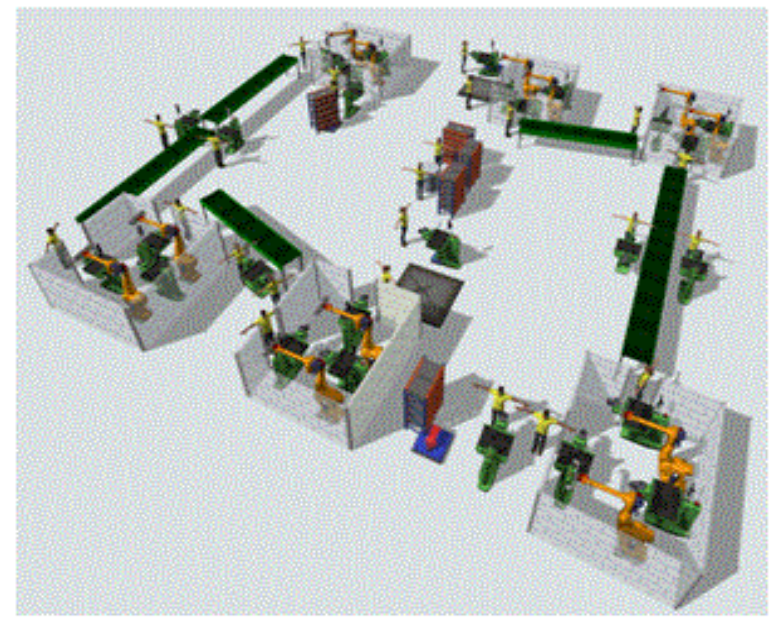

Figure 9: Simulation of current painting process using robots

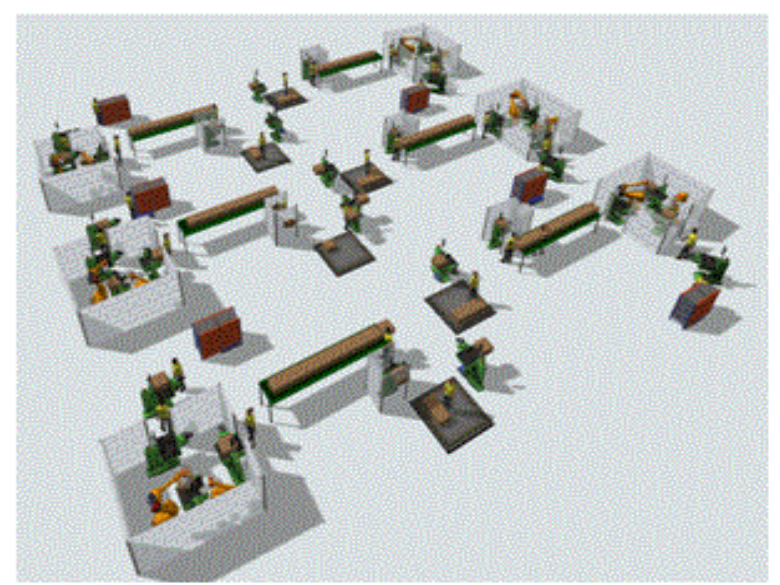

Figure 10: Simulation of proposed painting process for single color wares

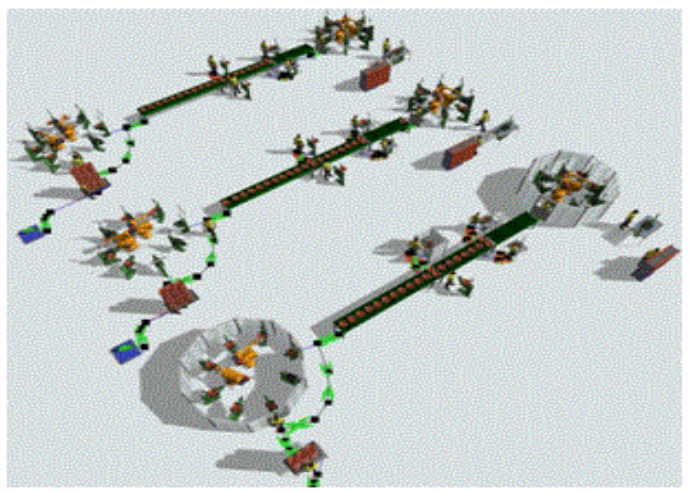

Figure 11: Simulation of proposed painting process for 2-colors wares

\section{Optimization equation}

In this study was analyzed costs and profit maximizing output decisions by looking at two different possible costs structures of single color ware and 2-colors ware. Profit equation is following,

Profit=TR-TC

Where,

TR is total revenues

$\mathrm{TC}$ is total costs

$$
\mathbf{T R}=\sum_{\mathrm{i}=1}^{\mathrm{n}} \mathrm{Ri} \times \mathbf{X i}
$$

Where,

$\mathrm{Ri}$ is revenues of product $\mathrm{i}$.

$\mathrm{Xi}$ is the units of output produced of product $\mathrm{i}$. $\mathrm{n}$ is numbers of product

The total cost equation following equality:

Total cost $=$ fixed costs + variable costs

In formula:

$$
\mathbf{T C}=\sum_{1=1}^{\mathrm{n}}(\mathbf{F C i}+\mathbf{V C i}) * \mathbf{X i}
$$

Where,

FCi is the fixed cost of product $\mathrm{i}$.

VCi the variable cost of product i.

Thus, from equation (1), (maximize profit equation is,

$$
\text { Profit }=\sum_{1=1}^{\mathrm{n}}(\mathbf{R i}-\mathbf{F C i}-\mathrm{VCi}) * \mathbf{X i}
$$

In this study we considered,

- The variable cost was considered only direct labor cost which was estimated at 1.8 USD per man-hr.

- The fixed costs of this painting production line were estimated at 31.25 USD/hour/painting station.

- The benefit or revenue of single color ware is 0.50 USD per unit.

- While the benefit or revenue of 2-colors ware is 1.50 USD per unit.

From the revenues and costs data above, by input the value into equation (4) be able to know how to plan for the painting production process in order to maximize profit. The output of products produced from this calculation, then it can specify how the production layout should be arranged. 


\section{Results and Analysis}

The simulation of current and the proposed painting production lines provides the following results,

A Simulation results

Table I.

Table II.

Table III.

The process simulation results of ceramic painting production as in the above table, analyzed as follows:

\section{Throughput}

To achieve the most utilization of the painting robots, the factory uses it 24 hours by 3 shifts of production. The working time for each shift is 8 hours. One and half hours allowanced for setup the machine and rest time of workers. Therefore, the working time is reduced to 6.5. hours per shift only.

The output of current production process is 715 pieces/shift/ line. For 2 lines, daily output will be 4,290 pieces/day.

Simulation result of the proposed painting production process for single color ware shown the output equal to 930 pieces/shift/ line. For 6 lines, daily output will be 16,740 pieces/day.

While the simulation result of the proposed painting production process for 2-colors ware shown the output equal to 615 pieces/ shift/line. For 3 lines, daily output will be 5,535 pieces/day.

\begin{tabular}{|l|l|}
\hline Table I. The results of current painting processes & \\
\hline Data & Current painting production process \\
\hline Number of production lines (lines) & 2 \\
\hline Throughput (pieces per day) & 4,290 \\
\hline Number of workers (persons) & 66 \\
\hline Productivity (unit/man/hour) & 2.71 \\
\hline
\end{tabular}

Table II. The results of proposed painting processes for single color ware

\begin{tabular}{|l|l|}
\hline \multicolumn{1}{|c|}{ Data } & Proposed painting production process for single color ware \\
\hline Number of production lines (lines) & 6 \\
\hline Throughput (pieces per day) & 16,740 \\
\hline Number of workers(persons) & 90 \\
\hline Productivity(unit/man/hour) & 7.75 \\
\hline
\end{tabular}

Table III. The results of proposed painting processes for 2-colors ware

\begin{tabular}{|l|l|}
\hline \multicolumn{1}{|c|}{ Data } & Proposed painting production process for 2- colors ware \\
\hline Number of production lines (lines) & 3 \\
\hline Throughput (pieces per day) & 5,535 \\
\hline Number of workers(persons) & 90 \\
\hline Productivity(unit/man/hour) & 3.84 \\
\hline
\end{tabular}

\section{Throughput}

To achieve the most utilization of the painting robots, the factory uses it 24 hours by 3 shifts of production. The working time for each shift is 8 hours. One and half hours allowanced for setup the machine and rest time of workers. Therefore, the working time is reduced to 6.5 . hours per shift only.

The output of current production process is 715 pieces/shift/ line. For 2 lines, daily output will be 4,290 pieces/day.
Simulation result of the proposed painting production process for single color ware shown the output equal to 930 pieces/shift/ line. For 6 lines, daily output will be 16,740 pieces/day.

While the simulation result of the proposed painting production process for 2-colors ware shown the output equal to 615 pieces/ shift/line. For 3 lines, daily output will be 5,535 pieces/day. 


\section{Number of workers}

The current production process flow chart is shown in Fig. 2 the number of current production workers is 11 workers/shift/ line or total workers will be 66 workers per day. The proposed painting production process for single color will use only 5 workers/shift/line. So total required 90 workers per day. While the proposed painting production process for 2-colors ware required 10 workers/shift/line or total required 90 workers per day.

If considering just the number of workers, it looks like the proposed painting production process for single color looks the worst. But the number of production processes has increased 3 times from the present, while the number of workers has only increased 1.36 times.

\section{Productivity}

The number of workers used in production and output are mainly two variables that directly affect productivity. Productivity of current production process is 2.71 unit/man/hour. The proposed painting production process for single color ware achieved productivity at 7.75 unit/man/hour. While productivity of the proposed painting production process for 2-colors ware presented 3.84 unit/man/hour.

If key indicators are the productivity and output of production, the proposed for single color painting production process should be chosen to use as a new painting production process. This decision may not be fair. Because the proposed for 2-colors painting production process is designed for different types of products. Therefore, the number of workers and productivity level may not be able to get the most benefit from the painting robots. Decisions based on profit of production operations should be an appropriate indicator for the factory.

\section{Results of profit optimization equation}

Important information to consider before calculating are constraints of variables.

\section{1) Constraints}

- $\quad$ The demand for 2-colors wares is only 80,000 pieces per month. While demand of single color is unlimited.

- $\quad$ Production plan 26 days per month.

- $\quad$ The factory can invest to improve the process. But not investing in additional robots.

\section{2) Profit maximizing calculation}

Determined the value of each variables, found

FC1 is fixed cost of proposed for single color painting production process.

$\mathrm{FC1}=31.25 / 116.25=0.27 \mathrm{USD} /$ piece
- $\quad$ FC2 is fixed cost of proposed for 2-colors painting production process.

$\mathrm{FC} 2=31.25 / 76.87=0.41 \mathrm{USD} /$ piece.

- $\quad$ VC1 is variable cost of proposed for single color painting production process.

VC1 $=(1.80 \times 5) / 116.25=0.077$ USD $/$ piece .

- $\quad$ VC2 is variable cost of proposed for 2-colors painting production process.

$\mathrm{VC} 2=(1.80 \times 10) / 76.87=0.234 \mathrm{USD} /$ piece.

- $\quad \mathrm{X} 1$ is amount of single color wares

- $\quad \mathrm{X} 2$ is amount of 2-colors wares

From equation (4) and information we have,

Profit1 $=(0.50-0.27-0.077) * \mathrm{X} 1=0.153 \mathrm{X} 1$

Profit2 $=(1.50-0.41-0.234) * \mathrm{X} 2=0.856 \mathrm{X} 2$

The total profit is,

Profit $=0.153 \mathrm{X} 1+0.856 \mathrm{X} 2$

\begin{tabular}{|c|c|c|c|c|}
\hline $\begin{array}{l}\text { W a r e } \\
\text { type }\end{array}$ & $\begin{array}{r}\text { Painting } \\
\text { lines }\end{array}$ & $\begin{array}{r}\text { Output } \\
\text { (pcs/day) }\end{array}$ & $\begin{array}{r}\text { Unit profit } \\
\text { (USD) }\end{array}$ & Net profit (USD) \\
\hline $\begin{array}{l}\text { Single } \\
\text { color }\end{array}$ & 2 & 5,580 & 0.153 & 854 \\
\hline $\begin{array}{l}\text { Two } \\
\text { colors }\end{array}$ & 2 & 3,077 & 0.856 & 2,634 \\
\hline
\end{tabular}

Table V. Profit of new layout of painting production process option no.2

\begin{tabular}{|l|r|r|r|r|}
\hline ware type & Painting lines & $\begin{array}{r}\text { Output } \\
\text { (pcs/ } \\
\text { day) }\end{array}$ & Unit profit (USD) & $\begin{array}{r}\text { Net prof- } \\
\text { it (USD) }\end{array}$ \\
\hline $\begin{array}{l}\text { S i n g l e } \\
\text { color }\end{array}$ & 4 & 11,160 & 0.153 & 1,707 \\
\hline $\begin{array}{l}\text { Two col- } \\
\text { ors }\end{array}$ & 1 & 1,845 & 0.856 & 1,579 \\
\hline
\end{tabular}

Profit presented in table IV. is 3,488 USD/day which is more than profit presented in table $\mathrm{V}$ which have 3,287 . Therefore, when using maximum profits as an indicator to improve the painting production process using robots, there should be 2 production lines for single color wares and also 2 production lines for 2-colors wares as presented in From the production layout that shown in Fig. 12, then the simulation of the production process as shown in Fig. 13 shows that the output of the products the same 


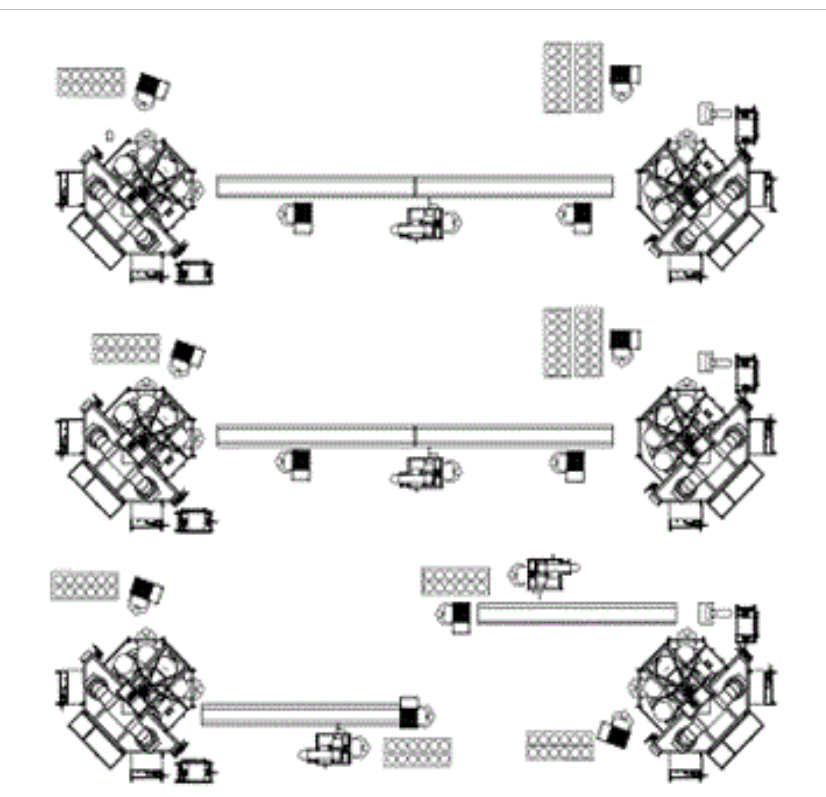

Figure 12: Layout of final proposed 4-painting production processes

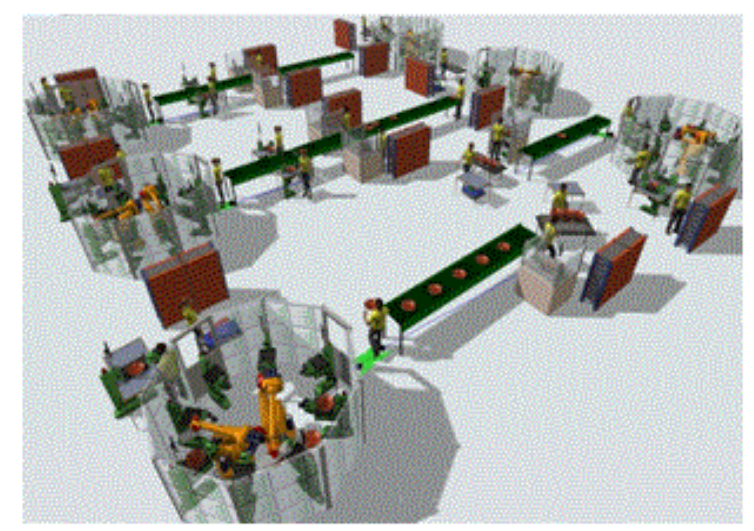

Figure 13: Layout of final proposed 4-painting production processes

as given in Table IV. This is because the variable values are the same. Therefore, the data in Table IV is accurate and reliable.

\section{Conclusion}

Process analysis using traditional engineering tools can provide better analysis results when combined with simulation software. FlexSim is proven as powerful 3D simulation program that is suitable for use in process simulation. Leads to improve the production process to be able to operate machinery such as ceramic painting robots which has invested a lot for the highest efficiency. Indicators for project selection, if only the output is insufficient. The maximum profits should also be used as indicators. To make the decision more accurate as the case study.

\section{References}

1. Negahban, A, and Smith, J. S. Simulation for manufacturing system design and operation: Literature review and analysis. Journal of Manufacturing Systems, 33(2), 201,.241-261.doi.10.1016/j.jmsy.2013.12.007

2. Kaale, R. L., Vega, D. D., Messner, K., Eitel, D. R., Johnson, D. E., McKniff, et.al Snyder, K.C. Time Value Stream next term Mapping as a Tool to Measure Patient Flow Through Emergency Department Triage. Annals of Emergency Medicine, 2005, 46(3). doi.org/10.1016/j.annemergmed.2005.06.398

3. R.M. Belokar, Sandeep Singh Kharb, Vikas Kumar, "An Application of Value Stream Mapping In Automobile Industry: A Case Study", International Journal of Innovative Technology and Exploring Engineering (IJITEE), 2012, ISSN: 2278-3075.

4. Burgess, N., Radnor, Z., \& Davies, R. Taxonomy of Lean in healthcare: A framework of Evaluating Activity and Impact. Proceedings of EurOMA conference 2009, 1-10.

5. Van Den Heuvel, J., Does, R. J., \& De Koning, H. Lean Six Sigma in a hospital. International Journal of Six Sigma and Competitive Advantage, 2006, 2(4), 377 - 388.doi: 10.1504/IJSSCA.2006.011566

6. Salleh Noor Azlina Mohd, Salmiah Kasolang, Ahmed Jaffar, Simulation of Integrated Total Quality Management (TQM) with Lean Manufacturing (LM) Practices in Forming Process Using Delmia Quest, Procedia Engineering 41,2012,1702-1707, doi.org/10.1016/j.proeng.2012.07.371

7. Monden, Y. Toyota production system: an integrated approach to justin-time. Industrial Engineering and Management Press Ohno, T., 1988. Toyota Production System: Beyond Large Scale Production. Productivity Press, Cambridge, MA.

8. Hammann, J. E. and N. A. Markovitch. Introduction to Arena simulation software. Simulation Conference Proceedings, 1995. Winter. Arlington, USA, CA: IEEE.doi.org/10.1145/224401.224674

9. John, B. and E. Jenson Joseph. Analysis and simulation of factory layout using ARENA. International Journal of Scientific and Research Publications, 2013, 3(2), 1-8.

10. Elena-Iuliana Gingu and Miron Zapciu, Improving layout and workload of manufacturing system using Delmia Quest simulation and inventory approach. International Journal of Innovative Research in Advanced Engineering (IJIRAE) (6). 2014.52-61.

11. Norhidayah M., Yupiter H.M., Roseleena J., Shaharudin A, Erry Y.A., Development of virtual assembly layout with modeling languages approach and Simulation using Delmia Quest, IIUM Engineering Journal, 13(1), 2011.doi: 10.31436/iiumej.v12i6.135

12. Ghosh, B. and King, P. Optimization of Smart Well Completion Design in the Presence of Uncertainty. Paper SPE 166008 presented at the SPE Reservoir Characterization and simulation Conference and Exhibition held in Abu Dhabi, UAE,2013,16 -18.doi.org/10.2118/166008-MS

13. Naus, M.M.J.J., Dolle, N. Jansen, J.D. Optimization of Commingled Production using Infinitely Variable Inflow Control Valves. Paper SPE 90959 presented at the SPE Annual Technical Conference and Exhibiti on,Houston,Texas,USA,2004,26-29.doi.org/10.2118/90959-PA

14. M. Beaverstock, A. Greenwood, E. Lavery, W. Nordgren, "Applied simulation modeling and analysis using FlexSim 3D simulation software", 4th Ed., FlexSim Software products Inc., 2011. 